Niniejsza publikacja jest dostępna na licencji Creative Commons. Uznanie autorstwa-Użycie niekomercyjne-Bez utworów zależnych 3.0 Polska. Pewne prawa zastrzeżone na rzecz autora. Zezwala się na wykorzystanie publikacji zgodnie z licencja - pod warunkiem zachowania niniejszej informacji licencyjnej oraz wskazania autora jako właściciela praw do tekstu. Treść licencji jest dostępna na stronie: http://creativecommons.org/licenses/by-nc-nd/3.0/pl/

Lingwistyka Stosowana 18: 3/2016, 1-11

\author{
Justyna ALNAJJAR
}

Uniwersytet Warszawski

\title{
Researching Up. An Applied Linguist's Investigations into Corporate Communication ${ }^{1}$
}

\begin{abstract}
:
Undertaking empirical research in global companies is a challenging task for applied linguists. Hermetic and closed as the corporate world remains, it opens up numerous research possibilities for applied linguists and lets them develop and test their models and theories. With the help of a case study, this paper shows how academic and corporate cultures meet head-on, the challenges an applied linguist may encounter when entering a corporate environment, and proposes solutions that may be helpful in overcoming difficulties.
\end{abstract}

\section{Introduction}

Nowadays, more and more research projects are devoted to investigating corporations. Researchers, in particular in the fields of management and economics, are interested in various aspects of the corporate world. Communication is one of the areas of their research (e.g. K. Nagel 2012, see summary in J. Zając 2013, also comments regarding communication audits in J. Alnajjar 2016). One might think, however, that it is linguists, in particular applied linguists who study language and communication, who should participate in research projects concerning corporate language and communication (see J. Alnajjar 2016). Indeed, slowly but steadily applied linguists are increasingly contributing to this area of research. Being relatively novice, applied linguists are bound to face certain difficulties when working in the world of corporations (see B. Crawford Camiciottoli 2015). In this paper, I discuss selected challenges that an applied linguist may be confronted with when entering a corporate environment. I focus in particular on challenges resulting from the asymmetry between applied linguists and research participants that occurs during fieldwork. I leave out aspects related to interculturality and multilingualism, which are strongly connected with corporate communication.

\footnotetext{
${ }^{1}$ A preliminary version of this paper was presented at the $1^{\text {st }}$ International Conference on Communication Across Cultures (COCAC): Negotiating and Resolving Conflicts, 6-7 November, 2015, Warsaw, Poland.
} 


\section{The Corporate World vs. The Academic World}

The corporate world and academic world inevitably differ. It is widely perceived that this differentiation is related to the fact that both worlds continue to develop their own cultures. The terms "corporate culture" and "academic/university culture" are often captured under "organisational culture", defined by G. Hofstede as "the collective programming of the mind that distinguishes the members of one group or category of people from another" (G. Hofstede 2001: 9). According to G. Hofstede, representatives of various cultures or groups can be distinguished on the basis of specific practices that they develop over the course of time, when working together on specific tasks. Practices are repetitive and enable the development of organisational standards that new members can learn with time. Practices encompass rituals, heroes, and symbols (G. Hofstede 2001: 394-395). Symbols refer to words used (either in a general or specialist language), gestures, pictures, and objects that have a specific meaning for the representatives of a given culture (G. Hofstede/ G.J. Hofstede/ M. Minkov 2010: 8). Heroes are dead or living, real or imaginary persons who represent certain features important within a given culture, whereas rituals are collective activities within a given culture, "socially essential" to achieve certain goals, such as greetings and social ceremonies. Rituals can also refer to discourses, i.e. to "the way language is used in text and talk, in daily interaction, and in communicating beliefs" (G. Hofstede/ G.J. Hofstede/ M. Minkov 2010: 8-9). Undeniably, in the case of academic culture and corporate culture, representatives perform work based on specific practices that differ to a high degree as a result of, above all, the various goals pursued in academia and in the corporate world. Whereas scholars are in the main interested in conducting research and transferring the results to society by providing education to future employees, boards of directors in corporations aim at yielding profit. In addition, companies' representatives attempt to develop tangible standards that they often write down so that it is easier to learn and perform repetitive tasks more efficiently. Research process, on the other hand, can hardly be captured in a list of prescribed rules that are, to a certain extent, intuitive. This may be depicted as an exhausting trekking tour, as presented in Figure 1 (see E. Harburg 1966: 470, cf. C. Riemer 2014: 17 and The Island of Research: online).

Research conducted by applied linguists is no exception. Indeed, an applied linguist begins his or her research journey at the bay of literature by reading a number of scholarly texts, and then enters the city of hope. In order to reach their final research aim, the applied linguist usually deals with designing an adequate research process, collecting, coding, analysing, assessing, and interpreting data. It should be stressed, however, that even within one research field or discipline - the example here being applied linguistics - there is no consensus as to which theories, methods, research design are best suited to (applied linguistic) investigation (see e.g. C. Coffin/ Th. Lillis/ K. O'Halloran 2010: 1). 


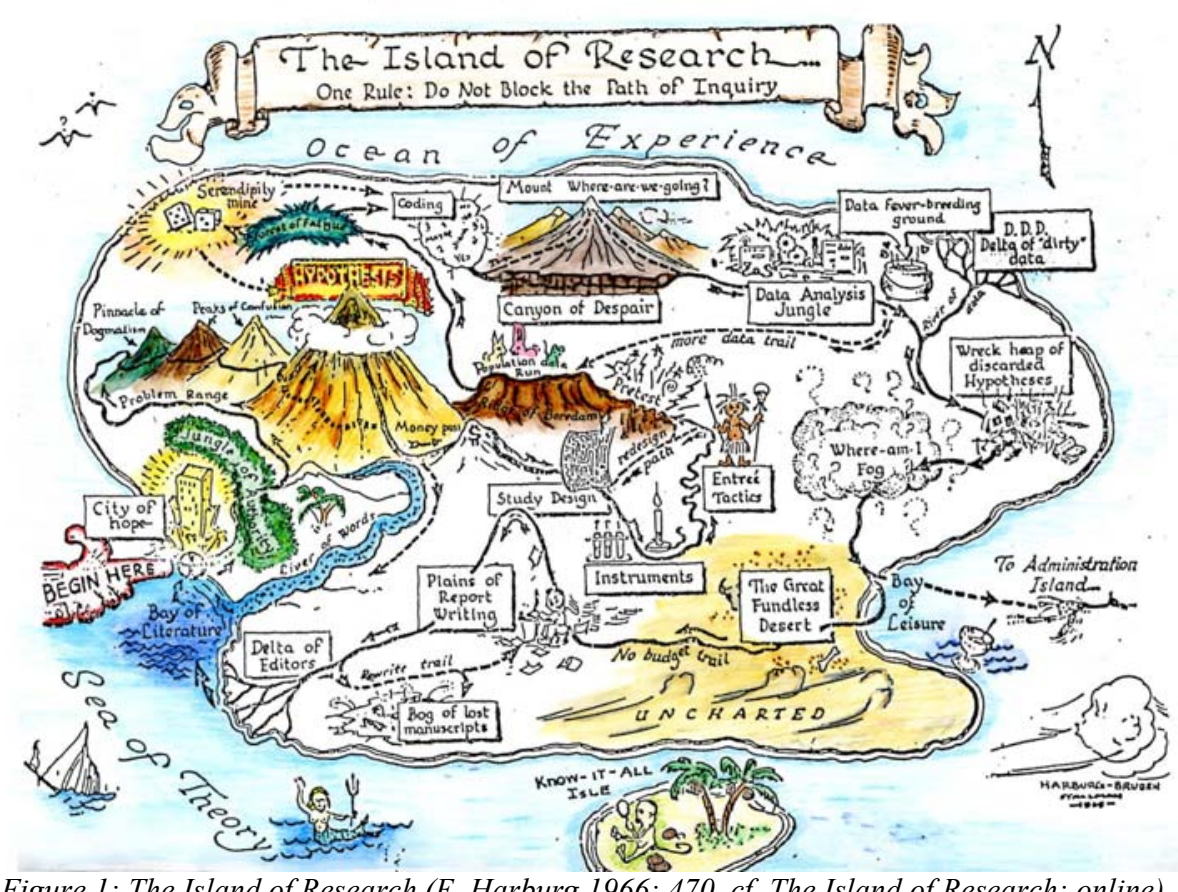

Figure 1: The Island of Research (E. Harburg 1966: 470, cf. The Island of Research: online)

Similarly, it may be noted that corporations differ and no two corporations are identical or conduct their business in precisely the same manner. Therefore, in this paper I will not focus on pointing out the differences between the two cultures in general. Instead, I will discuss in more detail what happens when applied linguists who are interested in researching actual corporate communication and corporate speak/language, enter (or attempt to) a corporate world to discover more and ultimately aim to have some impact upon corporate language and communication problems, and to subsequently enrich academic curricula. Aspects of undertaking research in corporate settings will be discussed here from the perspective of an applied linguist who conducted research into business communication audits (see J. Alnajjar 2015, 2016) in order to inform the conducting of communication audits from a linguistic perspective, and thus was obliged to gather data and spend some time in selected companies. The focus will be on collaboration between an applied linguist and corporate representatives throughout the research process.

\section{Research Project}

The research project into business communication audits in global corporations aimed in particular at defining communication audits, describing the communication audit process, in addition to specifying methodology and techniques for carrying out communication audits. It was conducted from a linguistic perspective with a focus on intercultural and interlingual communication in global virtual teams. In order to arrive at a successful conclusion, it was pivotal to gather authentic data. It was decided that for this purpose the best option would be a research process in the form of a 
multiple/collective case study. In other words, the research project consisted of particular, qualitative cases, i.e. project teams were selected to provide an insightful picture of how communication audits in international project teams can be conducted in practice. The aim of the research project was to devise an analytical generalisation, more specifically communication audit model and procedures (J. Alnajjar 2016). From a researcher's point of view, every case study consisted of six stages:

1. Contact with the company;

2. Collecting information about the company and the project team to be audited;

3. Contact with the project team;

4. Interviews and observations, collecting language data;

5. Data compiling, processing, analysing, and interpreting;

6. Reports, presentation, discussion.

In short, I first established contact with project-based companies and collected information about them via documents, interviews, walk-arounds. Establishing a general knowledge about the companies' policy, specific goals, etc., and having secured top management's support for my research project, I moved on to initiate contact with the project teams within these companies, whose communication I was intending to investigate. At the beginning, I usually introduced myself in a letter addressed to the project team that was delivered to the entire team by a representative of top management, explaining the reasons for the collaboration with the researcher and "introducing" the researcher to the project team. Next, I discussed various issues with the project managers, who then arranged meetings and interviews with project team members for me. Together, we also fixed dates during which I could conduct observation in situ and over the phone. I also received selected email communication between the team members, which I could sort, code, analyse, and interpret at a later stage, in tandem with data from the interviews and observations that had to be transcribed. Finally, I compiled a linguistic report from each case study, presented the research results to the teams and/or managers, and discussed selected points with them. The research work during the stages above was much more complex than this brief outline suggests. However, it would be impossible to present all aspects within this paper. I provide full details in J. Alnajjar (2016). Here, I would like to focus on specific aspects of this work that posed particular difficulties due to the asymmetry (inequality) between the applied linguist and the research participants.

\section{Applied Linguist's Role(s)}

Based on the description of the research project (Section 2), it may be deduced that when researching corporate communication, an applied linguist must conduct both linguistic analysis and fieldwork. While it is clear that in order to research communication, an applied linguist will carry out text and/or discourse/conversation analysis and investigate selected aspects of collected texts/discourses (see e.g. J. Spitzmüller/ I. H. Warnke 2011), the issue of how fieldwork should be organised is less obvious. Therefore, in this paper I focus, in particular, on aspects of fieldwork, essentially ethnographic in nature, as it should provide a certain degree of understanding into the internal structure and corporate culture of the business entity under study. Fieldwork enables an applied linguist to comprehend the (dynamic) 
context of the communication under investigation (so-called contextualisation), providing the detail necessary to make links between meaning and social relations, interactional histories, and institutional regimes (B. Rampton 2010: 236). B. Rampton situates such fieldwork within the constraints of linguistic ethnography and claims that linguistic ethnography investigates "communication within the temporal unfolding of social processes that involve" (1) persons, (2) situated encounters, in addition to (3) institutions, networks, and communities of practices (ibid.). Following B. Rampton, these three elements, characterised by a number of details, are strongly interlinked (ibid., see also F. English/ T. Marr 2015: 9). Similarly, ethnographers of communication attempt to understand people's language, communication, and their social practices in communities of practice (J. Kaplan-Weinger/ Ch. Ullman 2015: 19). Without dwelling on the differences and similarities between linguistic ethnography and the ethnography of communication, it may be noted that in order to provide a detailed picture of actual communication within a corporation, the ethnographic approach is of great help (B. Crawford Camiciottoli 2015: 75-76). Therefore, it can be concluded that an applied linguist undertakes two roles when investigating corporate communication. He or she is on the one hand discourse analyst, and on the other hand linguistic/communication ethnographer. The former relates to analysing and interpreting language data, whereas the latter concerns fieldwork, collecting data, and studying cultural and contextual aspects of communication. Although, it should be noted that scholars dealing with linguistic ethnography capture both discourse analysis and ethnography:

They [researchers employing linguistic ethnography - J.A.] use ethnography to 'open up' linguistic analysis and linguistics to 'tie down' ethnographic insights ... To achieve this, they draw upon a wide variety of linguistic and discourse analytic traditions (for example, conversation analysis, textual analysis, quantitative variation analysis, corpus analysis, social semiotics) in combination with ethnography. This process of 'opening up' and 'tying down' may well distinguish linguistic ethnography. (S. Shaw/ F. Copland/ J. Snell 2015: 9)

Let us now focus on the challenges of the applied linguist's fieldwork and possible solutions to these challenges (Section 4).

\section{Dealing with Researching Up in the Field}

Incorporating fieldwork in the investigation of corporate communication is helpful when carrying out text and discourse analysis, and subsequently comprehensively informing the linguistic body of knowledge. There are, however, numerous obstacles and points to consider when working in the field, discussed in more detail below. These mainly relate to asymmetry/inequality between the applied linguist and the companies' representatives, which according to B. J. Warneken and A. Wittel (1997) can be called "research up" (see also "studying up" in F. Breuer 2011: online). Such asymmetry is bound to develop as an applied linguist offers to investigate communication that according to corporate representatives "works fine" and does not need to be optimised in any respect. What is more, corporate representatives rely on facts, clear answers and solutions delivered at a fast pace and promising financial profit. An applied linguist can hardly meet the expectations of such a highly profitoriented corporate environment. The linguistic approach to communication that an 
applied linguist offers (based on observations, interviews, text analysis, amongst other things) is usually regarded by professionals as slow and, above all, without immediate financial profit. Professionals are often also sceptical about the research results and the possibility of measuring communication, which is in fact immeasurable. Some consider linguistic intervention to be unnecessary or even disturbing in a dynamic corporate environment. Therefore, it is not surprising that an applied linguist and their work are not given any priority. This is reflected, for example, in the applied linguist's emails and phone calls, necessary to contact the company's representatives, being ignored. In short, the first challenge of an applied linguist intending to investigate communication in global corporations is to obtain access to the field itself and ensure the support of top management for the entire research process.

\section{Challenge 1: Acceptance by top management}

Before being able to start working in the field, it is necessary to secure top managers' acceptance for the research project. For an applied linguist interested in conducting a research project into corporate communication, it is exceptionally difficult to be taken seriously by top management. As mentioned above, linguistic work is usually viewed as superfluous and not promising any financial profit.

\section{Possible solution}

It is helpful to contact top management through a mutual contact often called "gatekeeper". A gatekeeper can be a friend, a friend of a friend or colleague. A gatekeeper can also emerge from chance encounters (see T. Rapley 2007: 43). They are usually a member of management and will facilitate contact with top management. The gatekeeper may be viewed as a "spokesperson" for the linguist in conversations with other members of the company (ibid.), convincing other corporate representatives of the potential profit linguistic research can bring. In short, contact with senior management is usually made possible through the personal relation with a gatekeeper who ensures that it is worth trusting the linguist and letting him or her conduct research tasks within the company. It should be added that at the initial stage, the gatekeeper also acts as a "key participant" by explaining various things related to the company in question to the linguist (see J. Kaplan-Weinger/ Ch. Ullman 2015: 67).

\section{Challenge 2: Access to the field}

As mentioned above, when establishing contact with the company, researcher's questions, requests, and messages may go unanswered, even though top management has allowed access to the field and pledged their support. Therefore, an applied linguist is forced to send a number of polite reminders in order to discuss various issues relating to investigating communication. This can delay the start of the research process. In the case of the communication audits carried out in my research, this delay was around five months. Employees of the HR department and lower management appeared to not know how to deal with a linguist and above all, who should answer the questions related to the research project or how much information may be revealed and by whom. 


\section{Possible solution}

In order to access the field, a great deal of patience must be employed. An applied linguist should not be discouraged by unanswered emails or conversations revealing hardly any relevant information. In order to speed up the process, it is worth getting in touch with the gatekeeper, who might help to encourage other employees to collaborate with the linguists in a more active way. It may also be useful to copy the gatekeeper's email address to all messages sent, emphasising to the addressee that top management supports the research process and has authorised the researcher to be informed about various issues related to selected aspects of corporate communication.

\section{Challenge 3: Acceptance by actual informants (and respondents) ${ }^{2}$}

Having obtained general information relating to a given company and secured the support of top management, it may still be problematic for an applied linguist to be accepted by the actual informants of the study. They will usually wish to know directly why they are obliged to participate, what the purpose of the study is, and what advantages they may gain from it. They may also have fears and reservations related to, for example, retaining their post, if during the research process their mistakes were to be revealed. For the researcher, this usually means, amongst other actions, repeatedly explaining the aims of research, answering a number of questions that have already been answered, discussing organisational issues over again, convincing informants of the usefulness of the investigation, and, above all, ensuring confidentiality. At the same time, it is necessary for the linguist to develop rapport with informants in order to arrive at trustworthy results. All this not only costs time but also means that the researcher is required to develop certain soft skills and tactics in order to collaborate with actual informants.

\section{Possible solution}

In order to build trust and reach satisfying research results, an applied linguist is bound to move through certain stages of their role development in the field. It is significant to recognise that this role evolves with time, and they are unlikely to be fully accepted by informants from the start. The role develops in phases. We can tentatively distinguish four phases: presentation phase, provisional member phase, categorical member phase, and role disengagement phase (see J. Alnajjar 2016). In the presentation phase, a linguist is considered a stranger or a newcomer. During this phase, participants should be informed about the fact that academic research is going to be conducted with their help. Informants should also be provided with an overview of the research process. Therefore, sending a letter giving a brief description of research aims and tasks, and ensuring the confidentiality of data, is recommended. Such a letter may be sent to the informants via a representative of top management, on behalf of the researcher. Next, personal contact may be established between the linguist and selected informants over the phone, or in person, in order to discuss practical points related to the research

\footnotetext{
${ }^{2}$ According to N. K. Denzin (1978: 198), informants are persons who ideally trust the investigator and are willing to give information about their work, problems encountered, etc., whereas respondents limit the information shared with the investigator to a minimum.
} 
process (e.g. interviews schedule, form and schedule of observations, forms of communication, etc.). During this initial contact, the applied linguist can build a relationship with informants. Informants usually recognise the role of the linguist as a researcher in the second phase, i.e. provisional member phase. In this phase, the applied linguist conducts interviews and observations, and thus has a chance to speak with the informants in person both formally and informally during lunch and coffee breaks. This presents an opportunity for informants to directly ask the linguist about research aims and results. It is also a chance to pose further questions concerning the researcher's academic career, interests, history, etc. At the same time, the personal contact enables the applied linguist to develop a good and open relationship and to build trust. As a result, the linguist becomes a member of the community in which the informants work on a daily basis, even though he or she does not participate in the same work-related tasks as the informants. In due course, the applied linguist becomes a so-called "categorial member" of the informants' community. This happens in the third phase, during which the applied linguist becomes accepted during meetings and situations previously considered confidential, to which they were originally denied access. Furthermore, the informants become more willing to share information, including personal information, discuss facts, and exchange opinions. However, the applied linguist must be careful to not "go native", through meticulously documenting contact with the informants in a transparent way and thus keeping a research distance (see L. Schmelter 2014: 43). During the final stage of fieldwork, the applied linguist is confronted with removing themselves from the field. With friendships established, the applied linguist must be careful not to let informants influence research results, for example by strictly forbidding any form of advice by the informants. All in all, it is important that when undertaking fieldwork, the applied linguist recognises the various stages of his or her role development and allows enough time to move through them.

\section{Challenge 4: Research as intervention}

"Any form of research is an intervention that disturbs, influences or even changes the context in which the study is done" (U. Flick 2007: 123). Research activities in a business context pose a good example of such a disturbance. The research participants' daily work is disrupted and they are asked questions, to which in their view the answers are obvious. Sometimes the applied linguist might trigger insecurity in the participants by observing their work habits, which for example, from the participants' point of view might be interpreted as looking for a reason to fire them. All this may make the participants behave unnaturally or unwilling to share their knowledge or present sincere opinions. This, in turn, poses a big challenge for the applied linguist. Additionally, when informants are of a higher status than the linguist, the disturbance may be expressed explicitly and thus negatively influence the relationship between the applied linguist and the research participants. This might occur in the case of researching corporate communication.

\section{Possible solution}

The applied linguist's aim is to produce reliable results. Therefore, the linguist should take the opportunity to assure participants on various occasions (letters, coffee breaks, 
interviews, emails, phone calls, etc.) that research results will be used solely for academic purposes. It should be noted that the applied linguist should be prepared to repeat the same information many times on different occasions, requiring a great deal of patience. The way the relationship between the applied linguist and informants may develop has been discussed under Challenge 3. In principle, over time the presence of the applied linguist will be accepted by the participants. It can be added that in order to encourage informants to fully cooperate, the applied linguist should attempt to convince them about the academic purposes of research, thus making them further trust the researcher. This might be achieved by explaining the relevance of research results, more than once if need be. People are more willing to share information, discuss, and explore their daily professional issues, if they can expect new and credible insights afterwards. Consequently, this should lead to reaching good and trustworthy results on the part of the researcher.

\section{Conclusion}

Research into communication in global corporations is far more complex than presented in this paper. Above all, it requires the consideration of methodological solutions for the purposes of researching communication conducted in a so-called "third language" by professionals developing a "third culture" in the course of their collaboration. This paper, however, focuses solely on general research-up questions in the field of global corporations and leaves out challenges strictly related to intercultural and multilingual issues. It shows how linguistic and ethnographic approaches are interlinked when an applied linguist conducts research into corporate communication.

It may be concluded that applied linguists who would like to conduct research projects into communication in global corporations should, in the first instance accept that they will have a lower status than their informants and thus should employ a great deal of patience when setting up collaboration with industry partners. Once an applied linguist has entered the field, it is highly probable that the collaboration will go smoothly and above all will bring useful results. However, applied linguists should be aware of the fact that fieldwork may go relatively slowly and require movement through various phases of role development in the field. In addition, there will inevitably be the need to deal with certain fears, questions, and issues that may arise for both the applied linguist and corporate representatives throughout the research process.

Having gone through the challenges of fieldwork, an applied linguist may carry out interesting research projects in a dynamic corporate environment and attain valuable results, thus contributing to the development of business linguistics. Indeed, as hermetic and closed as the corporate world remains, it opens up numerous research possibilities for applied linguists and lets them develop and test their models and theories. It also enables them to collect invaluable research experience, which subsequently translates into the development of didactic material and enriches the curricula of tertiary courses. 


\section{References}

Alnajjar, J. (2016), Communication Audit in Globally Integrated R\&D Project Teams. A Linguistic Perspective. Frankfurt a. M. etc.

Alnajjar, J. (2015), Mixed Qualitative Methods in Conducting Business Communication Audits. In: Proceedings of the 14th European Conference on Research Methodology for Business and Management Studies ECRM 2015 Malta. Malta, 19. URL http://rc-bca.iksi.uw.edu.pl/documents/9957757/ 10906394/ Alnajjar_Justyna_ECRM2015.pdf. (Accessed 17 January 2016).

Breuer, F. (2011), The "Other" Speaks Up. When Social Science (Re)presentations Provoke Reactance from the Field. In: Forum Qualitative Social Research 12(2), Article 23. URL http://www.qualitative-research.net/index.php/fqs/article/view/

1667/3230. (Accessed 17 January 2016)

Coffin, C./ T. Lillis/ K. O’Halloran (2010), Introduction. In: C. Coffin/ T. Lillis/ K. O’Halloran (eds), Applied Linguistics Methods. A Reader. London/New York, $1-7$.

Crawford Camiciottoli, B. (2015), Challenges and Opportunities in Accessing Discourse Data in Business Settings: Some Reflections on Research Experiences. In: Hermes - Journal of Language and Communication in Business. 54-2015, URL http://ojs.statsbiblioteket.dk/index.php/her/article/view/22948/ 20058. (Accessed 13 February 2016)

Denzin, N.K. (1978), The Research Act. A Theoretical Introduction to Sociological Methods. 2nd ed., New York etc.

English, F./ T. Marr (2015), Why Do Linguistics? Reflective Linguistics and the Study of Language. London etc.

Flick, U. (2007), Managing Quality in Qualitative Research. Los Angeles etc.

Harburg, E. (1966), Research Map. In: American Scientist 54: 470.

Hofstede, G. (2001), Culture's Consequences. Comparing Values, Behaviors, Institutions, and Organizations Across Nations. Thousand Oaks/London/New Delhis.

Hofstede, G./ G.J. Hofstede/ M. Minkov (2010), Cultures and Organizations. Software of the Mind. Intercultural Cooperation and Its Importance for Survival. 3rd ed., New York etc.

Island of Research. URL http://blogs.yahoo.co.jp/kn_hosoi_hue/12115081.html. (Accessed 13 February 2016)

Kaplan-Weinger, J./ Ch. Ullman (2015), Methods of the Ethnography of Communication. Language in Use in Schools and Communities. New York/London.

Nagel, K. (2012), Professionelle Projektkommunikation. Mit sechs Fallbeispielen aus unterschiedlichen Branchen. Wien.

Rampton, B. (2010), Linguistic ethnography, interactional sociolinguistics and the study of identities. In: C. Coffin/ T. Lillis/ K. O'Halloran (eds), Applied Linguistics Methods. A Reader. London/New York, 234-250.

Rapley, T. (2007), Doing Conversation, Discourse and Document Analysis. Los Angeles etc. 
Riemer, C. (2014), Triangulation. In: J. Settinieri/ S. Demirkaya/ A. Feldmeier/ N. Gültekin-Karakoç/ C. Riemer (eds), Empirische Forschungsmethoden für Deutsch als Fremd- und Zweitsprache. Eine Einführung. Padeborn, 15-31.

Schmelter, L. (2014), Gütekriterien. In: J. Settinieri/ S. Demirkaya/ A. Feldmeier/ N. Gültekin-Karakoç/ C. Riemer (eds), Empirische Forschungsmethoden für Deutsch als Fremd- und Zweitsprache. Eine Einführung. Padeborn, 33-45.

Shaw, S./ F. Copland/ J. Snell (2015), An Introduction to Linguistic Ethnography: Interdisciplinary Explorations. In: Snell, J./ S. Shaw/ F. Copland (eds), Linguistic Ethnography. Interdisciplinary Explorations. Basingstoke/New York, 1-13.

Spitzmüller, J./ I. H. Warnke (2011), Discourse as a 'linguistic object': methodical and methodological delimitations. In: Critical Discourse Studies, Vol. 8, No. 2, May, 75-94.

Warneken, B.J./ A. Wittel (1997), Die neue Angst vor dem Feld. Ethnographisches research up am Beispiel der Unternehmensforschung. In: Zeitschrift für Volkskunde 93, 1-16. 